\title{
Effects of Sevoflurane and Propofol on Organ Blood Flow in Left Ventricular Assist Devices in Pigs
}

\author{
Paloma Morillas-Sendín, ${ }^{1}$ Emilio Delgado-Baeza, ${ }^{2}$ \\ María Jesús Delgado-Martos, ${ }^{2}$ Mónica Barranco, ${ }^{1}$ Juan Francisco del Cañizo, ${ }^{2}$ \\ Manuel Ruíz, ${ }^{3}$ and Begoña Quintana-Villamandos ${ }^{1,4}$

\begin{abstract}
${ }^{1}$ Department of Anesthesiology and Intensive Care, Gregorio Marañón University General Hospital, 28007 Madrid, Spain
${ }^{2}$ Department of Experimental Medicine and Surgery, Gregorio Marañón University General Hospital, 28007 Madrid, Spain

${ }^{4}$ Department of Pharmacology, Faculty of Medicine, Complutense University, 28040 Madrid, Spain
\end{abstract} \\ ${ }^{3}$ Department of Cardiac Surgery, Gregorio Marañón University General Hospital, 28007 Madrid, Spain
}

Correspondence should be addressed to Begoña Quintana-Villamandos; begoquinti@gmail.com

Received 26 March 2015; Revised 16 June 2015; Accepted 29 June 2015

Academic Editor: Giulio Agnetti

Copyright (C) 2015 Paloma Morillas-Sendín et al. This is an open access article distributed under the Creative Commons Attribution License, which permits unrestricted use, distribution, and reproduction in any medium, provided the original work is properly cited.

\begin{abstract}
The aim of this study was to assess the effect of sevoflurane and propofol on organ blood flow in a porcine model with a left ventricular assist device (LVAD). Ten healthy minipigs were divided into 2 groups (5 per group) according to the anesthetic received (sevoflurane or propofol). A Biomedicus centrifugal pump was implanted. Organ blood flow (measured using colored microspheres), markers of tissue injury, and hemodynamic parameters were assessed at baseline (pump off) and after 30 minutes of partial support. Blood flow was significantly higher in the brain (both frontal lobes), heart (both ventricles), and liver after 30 minutes in the sevoflurane group, although no significant differences were recorded for the lung, kidney, or ileum. Serum levels of alanine aminotransferase and total bilirubin were significantly higher after 30 minutes in the propofol group, although no significant differences were detected between the groups for other parameters of liver function, kidney function, or lactic acid levels. The hemodynamic parameters were similar in both groups. We demonstrated that, compared with propofol, sevoflurane increases blood flow in the brain, liver, and heart after implantation of an LVAD under conditions of partial support.
\end{abstract}

\section{Introduction}

Ventricular assist devices (VADs) are a promising therapeutic option for patients with advanced heart failure. VADs can act as a bridge to transplantation, as a destination therapy for patients with contraindications to transplantation, or as a bridge to a future recovery [1-3]. In the last few decades, VADs have been increasingly used in patients with end-stage heart failure, because heart transplantation is limited by a marked lack of donors [4].

The main purpose of a VAD is to maintain perfusion of vital organs. To improve the clinical output of the VAD, it is necessary to optimize perioperative conditions (continuousflow VAD, hemodynamic monitors, and anesthetic drugs) $[5,6]$. Although several studies show the effects of the VAD on organ blood flow (heart, brain, liver, and kidney) [7-9], the effect of anesthetics on organ blood flow in patients with a VAD has not been analyzed to date. Several studies have reported data on the response of organ blood flow to the administration of various anesthetics [10-13], although this effect remains unclear for VADs.

Given the beneficial effects of volatile anesthetics (sevoflurane) compared with intravenous anesthesia (propofol) on organ blood flow during cardiovascular surgery [14-17], we hypothesized that, compared with propofol, sevoflurane would increase organ blood flow in patients with a left VAD (LVAD). The aim of this study was to investigate differences between the effect of sevoflurane-based volatile anesthetic and that of propofol-based intravenous anesthetics on organ blood flow (brain, liver, heart, kidney, lung, and intestine) 


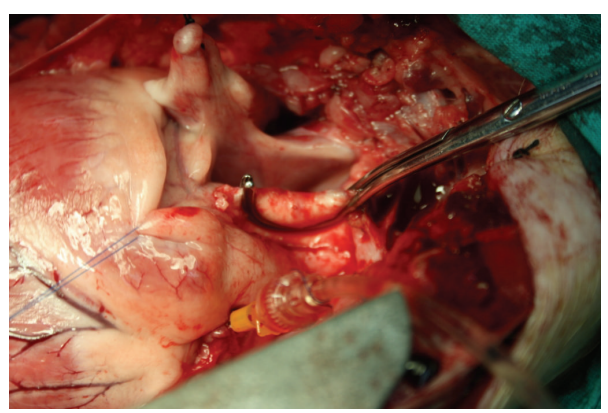

(a)

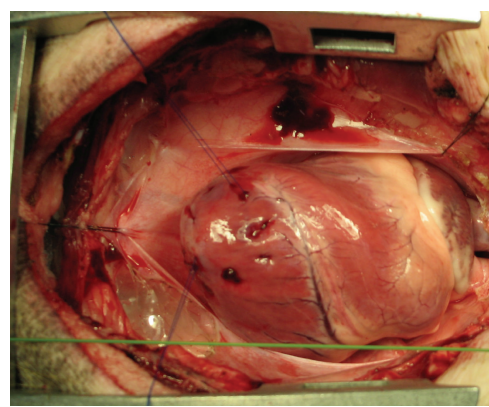

(b)

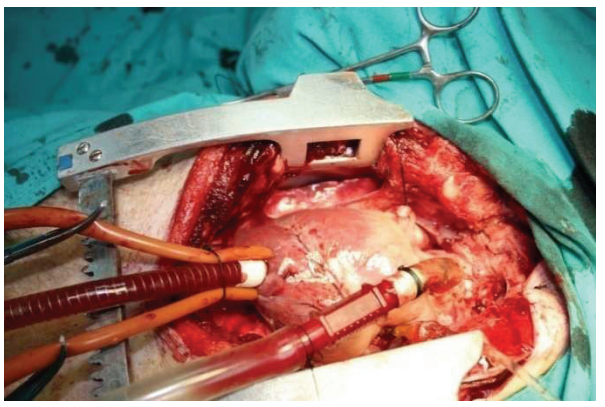

(c)

Figure 1: LVAD placement. Aortic partial cross-clamp (a). Implant of the input cannula through the apex of the left ventricle (b and c).

and to assess markers of tissue injury after implantation of an LVAD (continuous centrifugal pump) under conditions of partial support in a porcine model.

\section{Methods}

The animals used in our experiment were from the farm of the Technological Institute of Agrarian Development (EX 013-C) (Community of Madrid, Spain). The pigs were moved from this farm to the Experimental Medicine and Surgery Unit, Gregorio Marañón University General Hospital (ES280790000087), where they remained under a controlled environment until the intervention $\left(20-22^{\circ} \mathrm{C}\right.$ and relative humidity of $55 \%$ ). The study was performed in accordance with European Union guidelines on the protection of animals used for experimental and other scientific purposes (Directive 2010/63/EU and Spanish Royal Decree RD 53/2013 BOE) and was approved by the Ethics Committee, Gregorio Marañón University General Hospital, Madrid, Spain.

2.1. Experimental Design. The study was conducted with ten healthy minipigs. Animals were block-randomized (Microsoft Excel 2003) to receive either propofol in continuous perfusion as anesthetic maintenance (propofol group, $n=5$ ) or sevoflurane (sevoflurane group, $n=5$ ).

2.1.1. Anesthesia Protocol. The animals were simultaneously premedicated with intramuscular ketamine $20 \mathrm{mg} / \mathrm{kg}$ (Ketolar, Parke-Davis, Madrid, Spain) and atropine $0.04 \mathrm{mg} / \mathrm{kg}$ (Atropina Braun, Serra-Pamies, Reus, Spain). Pulse oximetry and electrocardiographic monitoring were performed in the operating room. The pigs were provided with oxygen $100 \%$ via a face mask, a $20 \mathrm{G}$ cannula was inserted into an ear vein, and anesthesia was induced with intravenous fentanyl $2.5 \mu \mathrm{g} / \mathrm{kg}$ (Fentanest, Kern Pharma, Barcelona, Spain) and propofol $4 \mathrm{mg} / \mathrm{kg}$ (Diprivan 1\%, AstraZeneca, Madrid, Spain). After intubation, the animal was connected to a volume-controlled ventilator (Dräger SA1, Dräger Medical AG, Lübeck, Germany) with $\mathrm{FIO}_{2}$ of 1 , an inspiratory: expiratory ratio of $1: 2$, a tidal volume of $12-15 \mathrm{~mL} / \mathrm{kg}$, and the respiratory rate adjusted to maintain normocapnia as previously described [18]. Anesthesia was maintained with intravenous fentanyl $(2.5 \mu \mathrm{g} / \mathrm{kg} / 30 \mathrm{~min})$ in all animals and propofol in continuous infusion (11$12 \mathrm{mg} / \mathrm{kg} / \mathrm{h}$ ) (propofol group) or 2\% sevoflurane (sevoflurane group). All animals received an infusion of saline solution $(8 \mathrm{~mL} / \mathrm{kg} / \mathrm{h})$. A $9 \mathrm{~F}$ arterial catheter was inserted into the right femoral artery and a pulmonary artery catheter (7.5 F SwanGanz CCOmbo catheter, Edwards Lifesciences, Irvine, CA, USA) connected to an oximetry monitor (Vigilance, Edwards Critical-Care Division, Irvine, CA, USA) was inserted into the right internal jugular vein.

2.1.2. Surgical Protocol. A Biomedicus 540 centrifugal pump was implanted in the minipigs undergoing continuous-flow support. After median sternotomy, the animal was heparinized at a dose of $4 \mathrm{mg} / \mathrm{kg}$. An aortic partial cross-clamp was applied (just for anastomosing the output cannula of the LVAD to the aorta) and a $2 \mathrm{~cm}$ aortotomy performed (Figure 1(a)). The output cannula of the LVAD was anastomosed to the ascending aorta, and the input cannula 
(23 F Medtronic Ultraflex, Metdtronic Inc., Minneapolis, USA) was placed through the apex of the left ventricle. The implant of the input cannula is practiced by placing two circular sutures (Figure 1(b)), and then the cannula was placed with two turnstiles around the cannula (Figure 1(c)). Finally, both cannulas were connected to the device. LVAD placement was without cardiopulmonary bypass and without cardioplegia. Console parameters were adjusted to obtain a pump flow of 50\% (partial support) of the baseline cardiac output (cardiac output before LVAD is initiated) using the pulmonary artery catheter for 30 minutes. Input flow was measured using an ultrasound transducer (EMTEC, Germany) attached to the input cannula of the device.

2.2. Organ Blood Flow Measurements. Colored microspheres (Dye-Trak, Triton Technology Inc., San Diego, CA, USA) were used to measure organ blood flow. Once the LVAD was implanted (before the start of LVAD, baseline), yellow microspheres (diameter of 12 microns) were injected into the left atrium (1.5 million microspheres per injection). The LVAD was then initiated, and violet microspheres were injected after 30 minutes of partial support. After each experiment, the animal was sacrificed using potassium chloride, and tissue samples of both brain hemispheres (right and left frontal lobe), heart (right and left ventricles), liver, lung (middle lobe of right lung), kidney, and ileum were obtained to measure organ blood flow. The basic principle of all deposition techniques for regional flow measurement is that the deposition is proportional to the flow (per unit volume or mass of tissue). Due to the movement of microspheres out of the capillaries into the interstitium, retention of microspheres is excellent. The idea is that deposited markers give a measure of flow per unit volume of tissue at the level of the capillaries. The microspheres were isolated from tissue by digestion with potassium hydroxide, they were centrifugated, the dyes were extracted from the colored microspheres, and the separation of colors and measurement of their concentration was performed by spectrometry $[19,20]$.

2.3. Markers of Tissue Injury. Serum levels of total bilirubin, alanine aminotransferase, aspartate aminotransferase, gamma-glutamyl transpeptidase, and alkaline phosphatase were evaluated as parameters of hepatobiliary function. Creatinine and urea were studied as parameters of renal function. Lactate dehydrogenase and lactate were measured as nonspecific indicators of tissue injury. All previously described markers of tissue injury and nitric oxide (NO) were studied at baseline (after implantation before turning it on) and 30 minutes after implantation of the LVAD.

2.4. Hemodynamic Measurements. The hemodynamic data included heart rate, mean arterial pressure, mean pulmonary arterial pressure, central venous pressure, pulmonary capillary wedge pressure, systemic vascular resistance index, pulmonary vascular resistance index, continuous cardiac output, and mixed venous oxygen saturation, all of which were recorded at baseline and 30 minutes after implantation of the LVAD. Body temperature was also studied.
2.5. Hematologic Parameters and Arterial Blood Gas Measurements. A femoral arterial catheter was used to perform the hematologic and blood gas analyses at baseline and 30 minutes after implantation of the LVAD.

2.6. Data Analysis and Statistics. The primary endpoint was organ blood flow in the LVAD, which was compared between the two groups. The variable was expressed as mean \pm SEM. We used the Kolmogorov-Smirnov test to analyze the distribution of quantitative variables; between-group comparisons were based on the $t$-test for independent samples. Statistical significance was set at a $P$ value of $<0.05$. The statistical analysis was performed using IBM SPSS Statistics for Windows, version 20.0 (IBM Corp, Armonk, NY, USA) and S-PLUS 6.1.

\section{Results}

3.1. Physiological Parameters. No differences were detected between the groups (sevoflurane versus propofol) in terms of age (143 \pm 7 versus $126 \pm 10$ days, $P=0.28)$, weight $(34 \pm 1$ versus $25 \pm 3 \mathrm{~kg}, P=0.052)$, or height $(93 \pm 2$ versus $87 \pm 1 \mathrm{~cm}$, $P=0.07)$.

3.2. Effect of Anesthetics on Organ Blood Flow. Blood flow was significantly higher in the brain (both frontal lobes) (Figures 2(a) and 2(b)), heart (both ventricles) (Figures 3(a) and 3(b)), and liver (Figure 4(a)) after 30 minutes of partial support in the sevoflurane group than in the propofol group, although no significant differences were recorded for the lung (Figure 4(b)), kidney (Figure 5(a)), or ileum (Figure 5(b)).

3.3. Effect of Anesthetics on Markers of Tissue Injury and Nitric Oxide. Serum levels of alanine aminotransferase and total bilirubin were significantly higher after 30 minutes of partial support in the group that received propofol. However, there were no significant differences between the groups in other parameters of liver function and kidney function or in lactic acid levels (Table 1). There were no differences between the groups in nitric oxide in plasma (Table 1).

3.4. Hemodynamic Parameters. No differences were found between the groups in pump flow of LVAD (propofol group $0.94 \pm 0.09 \mathrm{~L} / \mathrm{min}$ versus sevoflurane group $1.01 \pm$ $0.09 \mathrm{~L} / \mathrm{min})$.

The hemodynamic parameters showed marked stability in both groups; there were no significant differences in either the sevoflurane group or the propofol group before implantation of the LVAD and after 30 minutes of partial support (Table 2).

3.5. Hematologic Parameters and Blood Gas Analysis. No statistically significant differences were found between the groups for hemoglobin and hematocrit after 30 minutes (Table 3). Arterial oxygenation, systemic arterial $\mathrm{PCO}_{2}$, bicarbonate, and $\mathrm{pH}$ were similar in both groups before implantation and after 30 minutes of partial support (Table 3). 


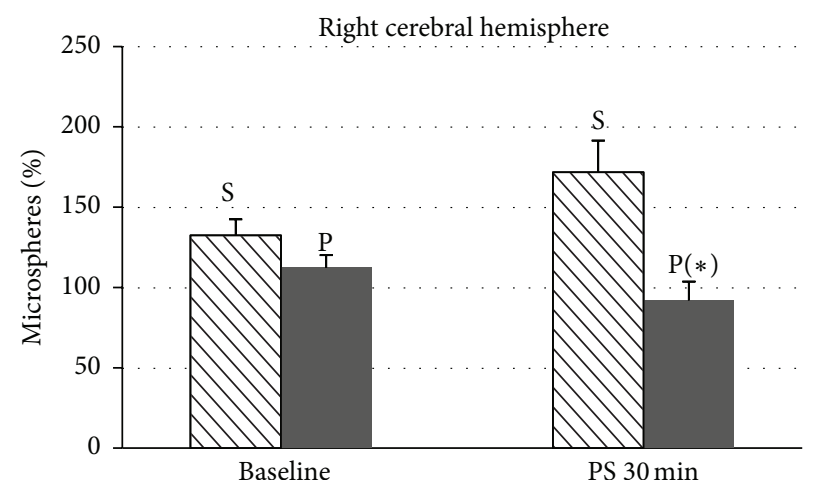

(a)

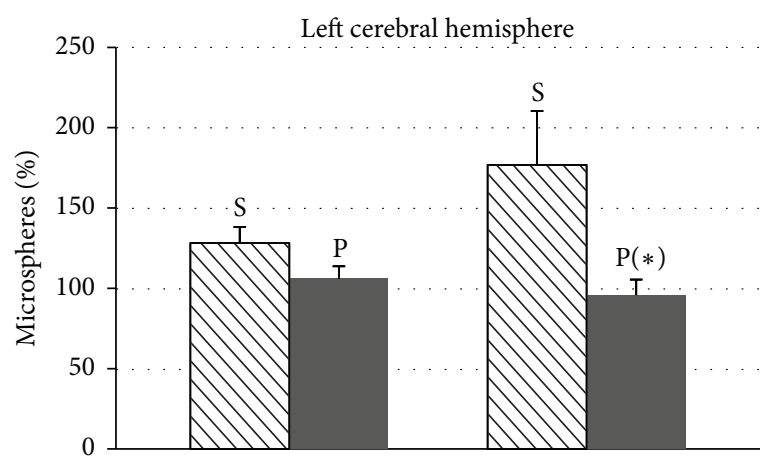

Baseline
PS $30 \mathrm{~min}$

(b)

FiguRE 2: Date are expressed as the mean \pm standard error of the mean. Cerebral blood flow in the right frontal lobe (a) and left frontal lobe (b) of pigs with a ventricular assist device in both groups, sevoflurane (S) and propofol (P), at baseline and after 30 minutes of partial support. Statistically significant differences are shown: ${ }^{*} P<0.05$ versus sevoflurane.

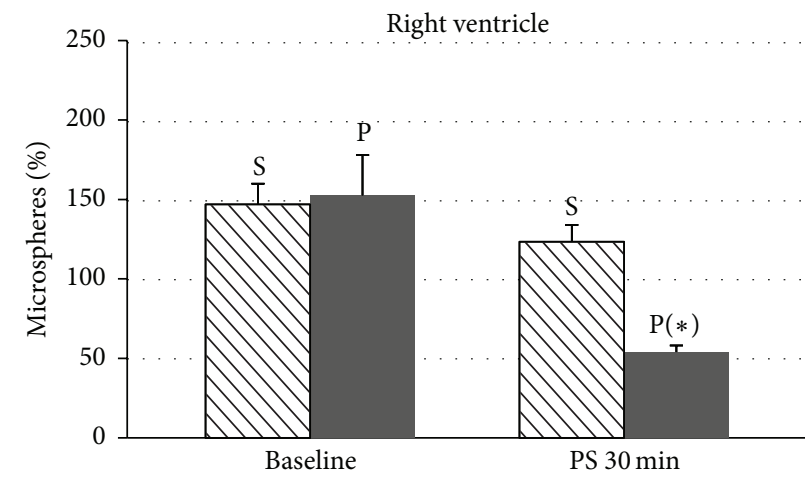

(a)

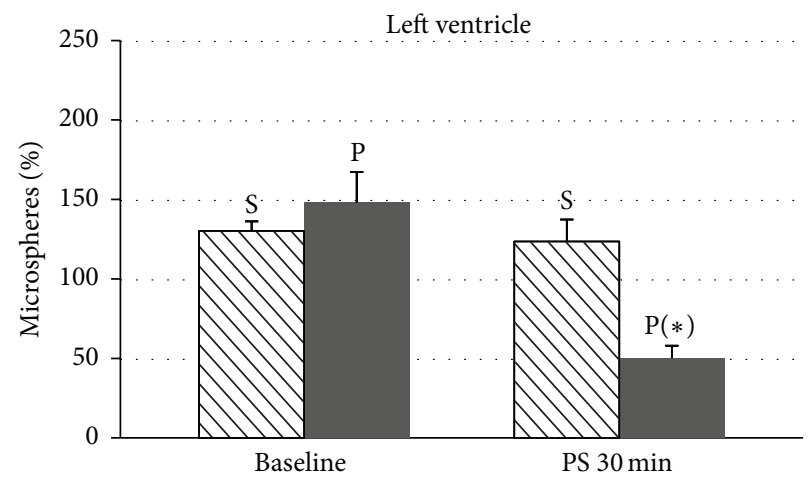

(b)

Figure 3: Date are expressed as the mean \pm standard error of the mean. Blood flow in the right ventricle (a) and left ventricle (b) of pigs with a ventricular assist device in both groups, sevoflurane $(\mathrm{S})$ and propofol $(\mathrm{P})$, at baseline and after 30 minutes of partial support. Statistically significant differences are shown: ${ }^{*} P<0.05$ versus sevoflurane.

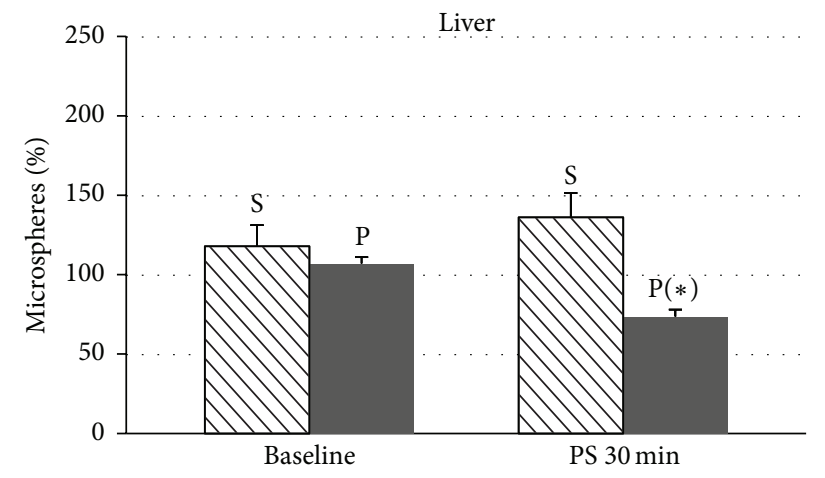

(a)

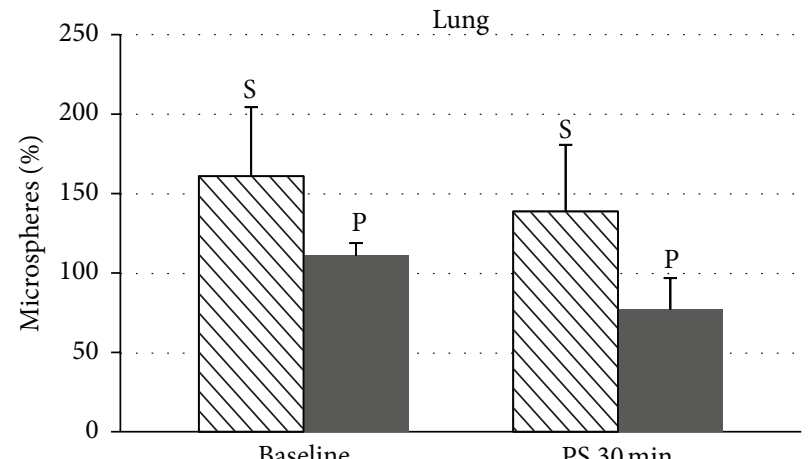

PS $30 \mathrm{~min}$

(b)

FIGURE 4: Date are expressed as the mean \pm standard error of the mean. Blood flow in the liver (a) and lung (b) of pigs with a ventricular assist device in both groups, sevoflurane $(\mathrm{S})$ and propofol $(\mathrm{P})$, at baseline and after 30 minutes of partial support. Statistically significant differences are shown: ${ }^{*} P<0.05$ versus sevoflurane. 


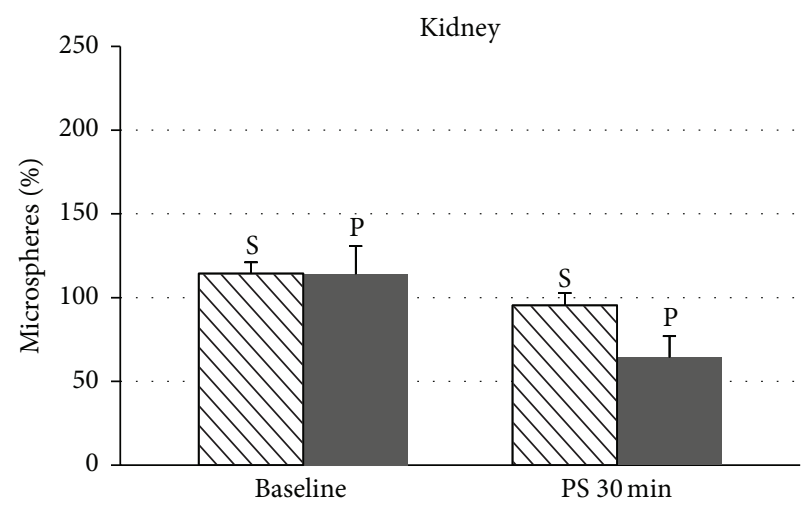

(a)

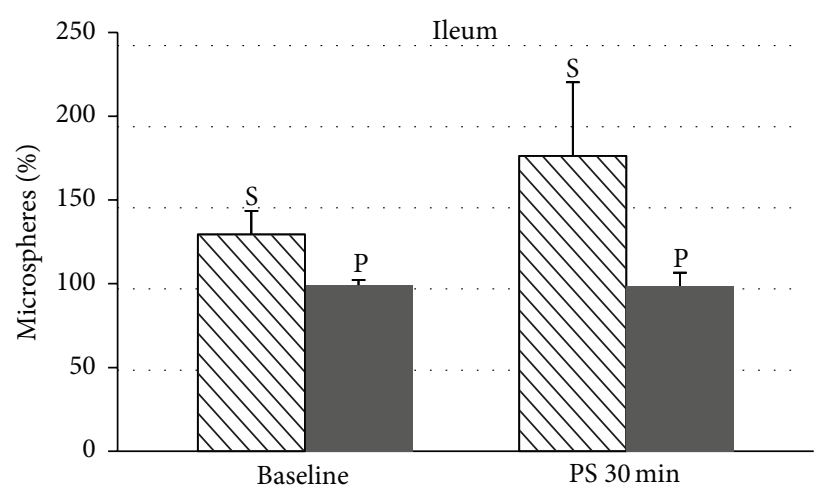

(b)

Figure 5: Date are expressed as the mean \pm standard error of the mean. Blood flow in the kidney (a) and ileum (b) of pigs with a ventricular assist device in both groups, sevoflurane (S) and propofol (P), at baseline and after 30 minutes of partial support.

\section{Discussion}

The results obtained show that, compared with propofol, anesthesia with sevoflurane increases blood flow in the brain, liver, and heart tissue after implantation of an LVAD under conditions of partial support in a porcine model. In addition, increased levels of serum markers of cellular injury in LVAD were observed with propofol. To our knowledge, this is the first study to demonstrate a beneficial effect of sevoflurane compared with propofol on organ blood flow in a Biomedicus 540 centrifugal pump in a porcine model. These findings justify further investigation to determine whether sevoflurane modifies organ blood flow in clinical settings.

The number of patients diagnosed with advanced heart failure is increasing worldwide, and LVAD is a pivotal treatment option for end-stage heart failure [21]. Because complications in the use of LVAD (multiple organ failure, right ventricular failure, neurological dysfunction, and arrhythmias) have been reported [22, 23], anesthesia and perioperative management of these critically compromised patients requires extensive monitoring, special anesthetic management with appropriate drugs, and expert postoperative care $[24,25]$.

4.1. Effect of Anesthetics on Organ Blood Flow. Several studies have reported changes in organ blood flow in response to the administration of volatile anesthetics and propofol [11-13, 26-28], although this effect has not been analyzed during implantation of an LVAD. Sevoflurane and propofol are frequently used as maintenance anesthetics during placement of an LVAD [29]. Some authors have associated reduced cerebral blood flow with both drugs [12]; however, we only found greater cerebral blood flow in sevofluraneanesthetized animals with an LVAD. Patients with LVAD are associated with neurologic events. The most common causes are thromboembolism and hemorrhagic stroke and less frequent causes are ischemia due to low perfusion and air embolism [30]. However, we are not sure that a higher flow reduces the occurrence of ischemia due to air embolism. According to our results, sevoflurane could be a good option to lower the incidence of ischemia due to low perfusion in LVAD-supported patients.

The results of some studies support cardiac and hepatic protective effects of sevoflurane with respect to propofol after coronary artery surgery in humans $[14,16]$. Our results also support the beneficial effect of sevoflurane compared with propofol on the heart and liver in LVAD. However, no differences were observed with sevoflurane compared with propofol for blood flow in other organs (lung, kidney, and intestine). The different blood flow response to sevoflurane could be explained by its dose-dependent effect [26-28].

Propofol and sevoflurane are used during cardiac surgery. Propofol exerts cardioprotective effects by different mechanisms: in the isolated heart, it attenuates metabolic changes induced by exogenously applied hydrogen peroxide [31], reduces infarct size by inhibition of GSK- $3 \beta$ activity (propofol induces cardiac preconditioning) [32], and attenuates ischemia-reperfusion injury mediated through increase in nitric oxide synthase activity and NO production (cardiac function and coronary flow are improved with propofol) $[33,34]$. In our study there were no differences in NO between both groups: sevoflurane and propofol. Propofol attenuates the changes in myocardial tissue levels of adenine nucleotides and lactate during ischemia, reduces troponin I release on reperfusion after cardioplegic arrest in cardiopulmonary bypass in a model porcine [35], and shows antiarrhythmic effect during myocardial ischemia in rats [36]. However, cardiopulmonary bypass (CPB) is known to alter the plasma propofol concentrations (hemodilution, hypotension, hypothermia, isolation of the lungs from the circulation, and possible sequestration of drugs in the bypass circuit affect drugs plasma concentrations) [37].

Sevoflurane also induces preconditioning and attenuates myocardial ischemia/reperfusion injury via caveolin-3dependent cyclooxygenase-2 inhibition, AMP-activated protein kinase, and antioxidative effects in experimental studies [38-40]. Clinical studies show that sevoflurane provides cardioprotection in patients undergoing coronary artery bypass graft (CABG) [41], and there is some data that shows that troponin $\mathrm{T}$ levels after off-pump CABG were lower in 
TABLE 1: Markers of tissue injury and nitric oxide in both groups (propofol and sevoflurane) at baseline and 30 minutes after implantation of a left ventricular assist device.

\begin{tabular}{|c|c|c|c|}
\hline & $\begin{array}{c}\text { Propofol } \\
n=5\end{array}$ & $\begin{array}{c}\text { Sevoflurane } \\
n=5\end{array}$ & $P$ values \\
\hline \multicolumn{4}{|l|}{$\operatorname{ALT}(\mathrm{U} / \mathrm{L})$} \\
\hline Baseline & $29 \pm 2$ & $25 \pm 2$ & 0.221 \\
\hline PS $30^{\prime}$ & $29 \pm 2$ & $23 \pm 2$ & $0.048^{*}$ \\
\hline \multicolumn{4}{|l|}{ AST (U/L) } \\
\hline Baseline & $50 \pm 10$ & $35 \pm 3$ & 0.116 \\
\hline PS $30^{\prime}$ & $94 \pm 46$ & $44 \pm 3$ & 0.358 \\
\hline \multicolumn{4}{|c|}{ Bilirubin (mg/dL) } \\
\hline Baseline & $0.25 \pm 0.06$ & $0.13 \pm 0.02$ & 0.081 \\
\hline PS $30^{\prime}$ & $0.24 \pm 0.02$ & $0.12 \pm 0.04$ & $0.028^{*}$ \\
\hline \multicolumn{4}{|l|}{ GGT (U/L) } \\
\hline Baseline & $63 \pm 12$ & $55 \pm 8$ & 0.584 \\
\hline PS $30^{\prime}$ & $62 \pm 22$ & $47 \pm 8$ & 0.496 \\
\hline \multicolumn{4}{|l|}{$\mathrm{AP}(\mathrm{U} / \mathrm{L})$} \\
\hline Baseline & $82 \pm 8$ & $72 \pm 8$ & 0.428 \\
\hline PS $30^{\prime}$ & $89 \pm 12$ & $79 \pm 7$ & 0.507 \\
\hline \multicolumn{4}{|l|}{ LDH (U/L) } \\
\hline Baseline & $330 \pm 19$ & $331 \pm 13$ & 0.943 \\
\hline PS $30^{\prime}$ & $374 \pm 18$ & $347 \pm 27$ & 0.420 \\
\hline \multicolumn{4}{|c|}{ Creatinine (mg/dL) } \\
\hline Baseline & $0.44 \pm 0.03$ & $0.57 \pm 0.06$ & 0.085 \\
\hline PS $30^{\prime}$ & $0.45 \pm 0.03$ & $0.47 \pm 0.03$ & 0.596 \\
\hline \multicolumn{4}{|c|}{ Urea (mg/dL) } \\
\hline Baseline & $27.2 \pm 2.2$ & $22.2 \pm 0.9$ & 0.059 \\
\hline PS $30^{\prime}$ & $28.2 \pm 2.6$ & $22.2 \pm 1.2$ & 0.053 \\
\hline \multicolumn{4}{|l|}{ Lactic acid } \\
\hline Baseline & $1.5 \pm 0.5$ & $1.1 \pm 0.2$ & 0.453 \\
\hline PS $30^{\prime}$ & $1.5 \pm 0.3$ & $1.2 \pm 0.2$ & 0.434 \\
\hline \multicolumn{4}{|l|}{$\mathrm{NO}(\mu \mathrm{M})$} \\
\hline Baseline & $418 \pm 47$ & $691 \pm 47$ & 0.056 \\
\hline PS $30^{\prime}$ & $280 \pm 92$ & $478 \pm 92$ & 0.270 \\
\hline
\end{tabular}

Data are expressed as the mean \pm standard error of the mean. ALT: alanine transaminase; AST: aspartate aminotransferase; GGT: gamma-glutamyl transpeptidase; AP: alkaline phosphatase (AP); LDH: lactate dehydrogenase; NO: nitric oxide; PS: partial support. Statistically significant differences are shown. ${ }^{*} P<0.05$ propofol versus sevoflurane.

patients receiving sevoflurane compared to propofol [42]. In this context, cardioprotection by sevoflurane compared to propofol could also be superior in patients undergoing noncardiac surgery [43]. However, troponin $\mathrm{T}$ increased in patients undergoing repair of congenital heart defect with cardiopulmonary bypass anesthetized with propofol and sevoflurane [44]. In our study we did not use cardiopulmonary bypass (there was no ischemia/reperfusion) in LVAD implantation.

It is known that sevoflurane tends to cause vasodilatation cerebral, increases cerebral blood flow (CBF), and decreases cerebrovascular resistance [45]. However, propofol produces
TABLE 2: Hemodynamic parameters in both groups (propofol and sevoflurane) at baseline and 30 minutes after implantation of a left ventricular assist device.

\begin{tabular}{|c|c|c|c|}
\hline & $\begin{array}{c}\text { Propofol } \\
n=5\end{array}$ & $\begin{array}{c}\text { Sevoflurane } \\
n=5\end{array}$ & $P$ values \\
\hline \multicolumn{4}{|c|}{ HR (beats/min) } \\
\hline Baseline & $95 \pm 4$ & $89 \pm 9$ & 0.546 \\
\hline PS $30^{\prime}$ & $101 \pm 6$ & $101 \pm 6$ & 0.964 \\
\hline \multicolumn{4}{|c|}{$\mathrm{AP}_{\mathrm{m}}(\mathrm{mmHg})$} \\
\hline Baseline & $70 \pm 3$ & $65 \pm 5$ & 0.384 \\
\hline PS $30^{\prime}$ & $65 \pm 8$ & $74 \pm 7$ & 0.404 \\
\hline \multicolumn{4}{|c|}{$\mathrm{PAP}_{\mathrm{m}}(\mathrm{mmHg})$} \\
\hline Baseline & $23 \pm 2$ & $25 \pm 2$ & 0.506 \\
\hline PS $30^{\prime}$ & $27 \pm 1$ & $33 \pm 3$ & 0.083 \\
\hline \multicolumn{4}{|c|}{ CVP (mmHg) } \\
\hline Baseline & $15 \pm 1$ & $15 \pm 1$ & 0.856 \\
\hline PS $30^{\prime}$ & $14 \pm 3$ & $16 \pm 2$ & 0.584 \\
\hline \multicolumn{4}{|c|}{ CPP (mmHg) } \\
\hline Baseline & $18 \pm 1$ & $18 \pm 1$ & 0.471 \\
\hline PS $30^{\prime}$ & $15 \pm 0.5$ & $19 \pm 1$ & 0.052 \\
\hline \multicolumn{4}{|l|}{ SVRI } \\
\hline Baseline & $1583 \pm 199$ & $1368 \pm 143$ & 0.450 \\
\hline PS $30^{\prime}$ & $1128 \pm 173$ & $1433 \pm 234$ & 0.351 \\
\hline \multicolumn{4}{|l|}{ PVRI } \\
\hline Baseline & $171 \pm 65$ & $159 \pm 32$ & 0.877 \\
\hline PS $30^{\prime}$ & $217 \pm 37$ & $339 \pm 85$ & 0.269 \\
\hline \multicolumn{4}{|l|}{$\mathrm{CO}(\mathrm{L} / \mathrm{min})$} \\
\hline Baseline & $2.4 \pm 0.3$ & $3 \pm 0.3$ & 0.185 \\
\hline PS $30^{\prime}$ & $2.5 \pm 0.4$ & $3.1 \pm 0.4$ & 0.347 \\
\hline \multicolumn{4}{|l|}{$\mathrm{SvO}_{2}(\%)$} \\
\hline Baseline & $77 \pm 4$ & $82 \pm 3$ & 0.429 \\
\hline PS $30^{\prime}$ & $82 \pm 1$ & $89 \pm 3$ & 0.150 \\
\hline \multicolumn{4}{|l|}{$T\left({ }^{\circ} \mathrm{C}\right)$} \\
\hline Baseline & $35.1 \pm 0.2$ & $35.9 \pm 0.3$ & 0.080 \\
\hline PS $30^{\prime}$ & $33.9 \pm 0.4$ & $34.6 \pm 0.4$ & 0.332 \\
\hline
\end{tabular}

Data are expressed as the mean \pm standard error of the mean. HR: heart rate; $\mathrm{AP}_{\mathrm{m}}$ : mean arterial blood pressure; $\mathrm{PAP}_{\mathrm{m}}$ : pulmonary artery mean pressure; CVP: central venous pressure; CPP: pulmonary capillary wedge pressure; SVRI: systemic vascular resistance index; PVRI: pulmonary vascular resistance index; $\mathrm{CO}$ : continuous cardiac output; $\mathrm{SvO}_{2}$ : mixed venous oxygen saturation; $T$ : temperature; PS: partial support.

cerebral vasoconstriction indirectly by reducing cerebral metabolism and causes a decrease in CBF that is well matched to cerebral metabolism [46]. Regarding why in our study sevoflurane increases CBF, Kaisti et al. [12] confirmed that $\mathrm{CBF}$ is lower with propofol than with sevoflurane.

4.2. Effect of Anesthetics on Markers of Tissue Injury. The objective of a VAD is to maintain adequate organ perfusion [2]. However, liver dysfunction has been observed despite adequate hemodynamic support with an LVAD [47]. Some 
TABLE 3: Hematologic parameters and blood gas analysis in both groups (propofol and sevoflurane) at baseline and 30 minutes after implantation of a left ventricular assist device.

\begin{tabular}{|c|c|c|c|}
\hline & $\begin{array}{c}\text { Propofol } \\
n=5\end{array}$ & $\begin{array}{c}\text { Sevoflurane } \\
n=5\end{array}$ & $P$ values \\
\hline \multicolumn{4}{|l|}{$\mathrm{pH}$} \\
\hline Baseline & $7.4 \pm 0.03$ & $7.4 \pm 0.02$ & 0.314 \\
\hline PS $30^{\prime}$ & $7.3 \pm 0.03$ & $7.4 \pm 0.02$ & 0.583 \\
\hline \multicolumn{4}{|c|}{$\mathrm{PO}_{2}(\mathrm{mmHg})$} \\
\hline Baseline & $503 \pm 24$ & $425 \pm 42$ & 0.147 \\
\hline PS $30^{\prime}$ & $492 \pm 43$ & $483 \pm 25$ & 0.867 \\
\hline \multicolumn{4}{|c|}{$\mathrm{PCO}_{2}(\mathrm{mmHg})$} \\
\hline Baseline & $35 \pm 2$ & $38 \pm 2$ & 0.428 \\
\hline PS $30^{\prime}$ & $38 \pm 3$ & $42 \pm 3$ & 0.322 \\
\hline \multicolumn{4}{|c|}{$\mathrm{HCO}_{3}^{-}(\mathrm{mmol} / \mathrm{L})$} \\
\hline Baseline & $22 \pm 1$ & $26 \pm 1$ & 0.073 \\
\hline PS $30^{\prime}$ & $21 \pm 1$ & $24 \pm 1$ & 0.052 \\
\hline \multicolumn{4}{|l|}{$\mathrm{Hb}(\mathrm{g} / \mathrm{dL})$} \\
\hline Baseline & $7.0 \pm 0.1$ & $7.4 \pm 0.4$ & 0.337 \\
\hline PS $30^{\prime}$ & $8.0 \pm 0.5$ & $8.3 \pm 0.7$ & 0.730 \\
\hline \multicolumn{4}{|l|}{ Hct (\%) } \\
\hline Baseline & $19.7 \pm 0.3$ & $21.9 \pm 1.2$ & 0.148 \\
\hline PS $30^{\prime}$ & $22.5 \pm 1.4$ & $24.5 \pm 2.0$ & 0.452 \\
\hline
\end{tabular}

Data are expressed as the mean \pm standard error of the mean. $\mathrm{PO}_{2}$ : partial pressure of oxygen; $\mathrm{PCO}_{2}$ : partial pressure of carbon dioxide; $\mathrm{HCO}_{3}{ }^{-}$: bicarbonate; Hb: hemoglobin; Hcto: hematocrit; PS: partial support.

authors have reported hyperbilirubinemia in patients following implantation of an LVAD by hepatic sinusoid endothelial dysfunction [48] or cardiac congestion [49]. In our study, total bilirubin was higher in propofol-anesthetized animals than in sevoflurane-anesthetized animals; this finding was consistent with reduced blood flow in the liver and heart with respect to sevoflurane-anesthetized pigs.

Bernard et al. [50] found a portal blood flow decreased at both 1.2 and $2 \mathrm{MAC}$ sevoflurane, whereas an increase in hepatic arterial blood flow was recorded at 2 MAC. These findings could explain why sevoflurane increases hepatic blood flow in our study.

4.3. Benefit of the Results for the Clinics. In our study, the use of sevoflurane leads to better outcomes after LVAD implantation by optimizing blood flow in the heart, brain, and liver. Although the necessary time to place an LVAD is short, the use of volatile anesthetic in cardiac surgery potentially reduces long-term cardiovascular complications and mortality [51]. Furthermore, intraoperative and postoperative sevoflurane administration in patients undergoing off-pump CABG could improve the cardioprotective effect compared with patients who received sevoflurane only in the intraoperative period [42]. It is possible because there is a disposable delivery system (AnaConDa) that is designed for halogenated sedation of patients in ICU [42]. LVAD, biventricular assist device (BIVAD), and extracorporeal membrane oxygenation (ECMO) are associated with a high incidence of complications (bleeding and tamponade requiring reexploration, right ventricular failure, respiratory failure, acute respiratory distress syndrome and pulmonary edema, neurologic complications, renal and hepatic failure, and infection) [5], and patients with complications are likely to require sedation and mechanical ventilation for a longer time period in ICU [52]. These patients could benefit from the sevoflurane effect over organs flow not only during the intraoperative, but also during the postoperative recovery period in the ICU.

4.4. Study Limitations. The present study is subject to a series of limitations. First, the LVAD is designed to be used in patients with heart failure; therefore, our results may not be directly applicable in clinical practice, because we used a healthy heart, as described elsewhere [53, 54]. This limitation should be addressed in an animal cardiogenic shock model. Second, since we studied the short-term effects of anesthetics (propofol and sevoflurane) in animals with an LVAD, the long-term effects of these drugs on organ blood flow warrant further investigation. Third, the effects of inhaled anesthetics $[26-28,55]$ and the intravenous anesthesia (propofol, opioids) $[56,57]$ may be dose-dependent. The concentration of sevoflurane we used represents approximately 1 minimum alveolar concentration, which is similar to the concentration used in other studies that show beneficial effects in a model of ischemia-reperfusion after thoracic-aortic occlusion in pigs [58].

We found that sevoflurane could be superior to propofol with respect to blood flow in the brain, liver, and heart tissue in a porcine model with LVAD. These findings may have significant clinical implications for anesthesiologists regarding the choice of sevoflurane in patients with an LVAD.

\section{Conflict of Interests}

The authors declare that there is no conflict of interests regarding the publication of this paper.

\section{Acknowledgment}

This work was supported by FIS (PI08/1480).

\section{References}

[1] S. R. Wilson, M. M. Givertz, G. C. Stewart, and G. H. Mudge Jr., "Ventricular assist devices the challenges of outpatient management," Journal of the American College of Cardiology, vol. 54, no. 18, pp. 1647-1659, 2009.

[2] M. E. Stone, "Current status of mechanical circulatory assistance," Seminars in Cardiothoracic and Vascular Anesthesia, vol. 11, no. 3, pp. 185-204, 2007.

[3] G. S. Francis, B. H. Greenberg, D. T. Hsu et al., "ACCF/AHA/ACP/HFSA/ISHLT 2010 clinical competence statement on management of patients with advanced heart failure and cardiac transplant: a report of the ACCF/AHA/ACP task force on clinical competence and training," Journal of the American College of Cardiology, vol. 56, no. 5, pp. 424-453, 2010. 
[4] J. Stehlik, L. B. Edwards, A. Y. Kucheryavaya et al., “The Registry of the International Society for Heart and Lung Transplantation: Twenty-seventh official adult heart transplant report-2010," The Journal of Heart and Lung Transplantation, vol. 29, no. 10, pp. 1089-1103, 2010.

[5] S. J. Allen and D. Sidebotham, "Postoperative care and complications after ventricular assist device implantation," Best Practice \& Research: Clinical Anaesthesiology, vol. 26, no. 2, pp. 231-246, 2012.

[6] F. Kerbaul, F. Collart, M. Bonnet, J. Villacorta, C. Guidon, and F. Gouin, "Perioperative management of ventricular assist devices," Annales Francaises d'Anesthesie et de Reanimation, vol. 22, no. 7, pp. 609-628, 2003.

[7] A. Sezai, M. Shiono, Y. Orime et al., "Renal circulation and cellular metabolism during left ventricular assisted circulation: comparison study of pulsatile and nonpulsatile assists," Artificial Organs, vol. 21, no. 7, pp. 830-835, 1997.

[8] S. Saito, S. Westaby, D. Piggot et al., "End-organ function during chronic nonpulsatile circulation," The Annals of Thoracic Surgery, vol. 74, no. 4, pp. 1080-1085, 2002.

[9] E. Tuzun, K. Eya, H. K. Chee et al., "Myocardial hemodynamics, physiology, and perfusion with an axial flow left ventricular assist device in the calf," ASAIO Journal, vol. 50, no. 1, pp. 47-53, 2004.

[10] W. J. Tranquilli, M. Manohar, C. M. Parks, J. C. Thurmon, M. C. Theodorakis, and G. J. Benson, "Systemic and regional blood flow distribution in unanesthetized swine and swine anesthetized with halothane + nitrous oxide, halothane, or enflurane," Anesthesiology, vol. 56, no. 5, pp. 369-379, 1982.

[11] A. Holmström and J. Åkeson, "Cerebral blood flow at 0.5 and 1.0 minimal alveolar concentrations of desflurane or sevoflurane compared with isoflurane in normoventilated pigs," Journal of Neurosurgical Anesthesiology, vol. 15, no. 2, pp. 90-97, 2003.

[12] K. K. Kaisti, J. W. Långsjö, S. Aalto et al., "Effects of sevoflurane, propofol, and adjunct nitrous oxide on regional cerebral blood flow, oxygen consumption and blood volume in humans," Anesthesiology, vol. 99, no. 3, pp. 603-613, 2003.

[13] A. Conti, D. G. Iacopino, V. Fodale, S. Micalizzi, O. Penna, and L. B. Santamaria, "Cerebral haemodynamic changes during propofol-remifentanil or sevoflurane anaesthesia: transcranial Doppler study under bispectral index monitoring," British Journal of Anaesthesia, vol. 97, no. 3, pp. 333-339, 2006.

[14] P. F. Conzen, S. Fischer, C. Detter, and K. Peter, "Sevoflurane provides greater protection of the myocardium than propofol in patients undergoing off-pump coronary artery bypass surgery," Anesthesiology, vol. 99, no. 4, pp. 826-833, 2003.

[15] S. G. De Hert, P. J. Van Der Linden, S. Cromheecke et al., "Cardioprotective properties of sevoflurane in patients undergoing coronary surgery with cardiopulmonary bypass are related to the modalities of its administration," Anesthesiology, vol. 101, no. 2, pp. 299-310, 2004.

[16] S. Lorsomradee, S. Cromheecke, S. Lorsomradee, and S. G. de Hert, "Effects of sevoflurane on biomechanical markers of hepatic and renal dysfunction after coronary artery surgery," Journal of Cardiothoracic and Vascular Anesthesia, vol. 20, no. 5, pp. 684-690, 2006.

[17] P. Sánchez-Conde, J. M. Rodríguez-López, J. L. Nicolás et al., "The comparative abilities of propofol and sevoflurane to modulate inflammation and oxidative stress in the kidney after aortic cross-clamping," Anesthesia and Analgesia, vol. 106, no. 2, pp. 371-378, 2008.
[18] B. Quintana-Villamandos, G. J. Rodríguez-Bernal, R. PérezCaballero et al., "Severe hypoxaemia with a left ventricular assist device in a minipig model with an undiagnosed congenital cardiac disease," Laboratory Animals, vol. 46, no. 1, pp. 77-80, 2012.

[19] F. W. Prinzen and J. B. Bassingthwaighte, "Blood flow distributions by microsphere deposition methods," Cardiovascular Research, vol. 45, no. 1, pp. 13-21, 2000.

[20] G. J. Rodríguez-Bernal, J. J. Sańchez-Hernández, P. Morillas et al., "Effects of ventricular assist devices on cerebral blood flow: comparison of pulsatile-flow and continuous-flow devices," Experimental and Clinical Cardiology, vol. 20, no. 1, pp. 16151625, 2014.

[21] J. Garbade, H. B. Bittner, M. J. Barten, and F.-W. Mohr, "Current trends in implantable left ventricular assist devices," Cardiology Research and Practice, vol. 2011, Article ID 290561, 2011.

[22] M. Jessup and I. J. Núñez-Gil, "Insuficiencia cardiaca y asistencias ventriculares: nuevas respuestas para antiguas preguntas," Revista Española de Cardiología, vol. 61, no. 12, pp. 1231-1235, 2008.

[23] S. A. S. Von Ruden, M. A. Murray, J. L. Grice, A. K. Proebstle, and K. J. Kopacek, "The pharmacotherapy implications of ventricular assist device in the patient with end-stage heart failure," Journal of Pharmacy Practice, vol. 25, no. 2, pp. 232-249, 2012.

[24] B. Mets, "Anesthesia for left ventricular assist device placement," Journal of Cardiothoracic and Vascular Anesthesia, vol. 14, no. 3, pp. 316-326, 2000.

[25] M. Feussner, C. Mukherjee, J. Garbade, and J. Ender, "Anaesthesia for patients undergoing ventricular assist-device implantation," Best Practice \& Research: Clinical Anaesthesiology, vol. 26, no. 2, pp. 167-177, 2012.

[26] M. Manohar and C. M. Parks, "Porcine systemic and regional organ blood flow during 1.0 and 1.5 minimum alveolar concentrations of sevoflurane anesthesia without and with 50\% nitrous oxide," The Journal of Pharmacology and Experimental Therapeutics, vol. 231, no. 3, pp. 640-648, 1984.

[27] P. F. Conzen, B. Vollmar, H. Habazettl, E. J. Frink, K. Peter, and K. Messmer, "Systemic and regional hemodynamics of isoflurane and sevoflurane in rats," Anesthesia and Analgesia, vol. 74, no. 1, pp. 79-88, 1992.

[28] M. W. Crawford, J. Lerman, M. Pilato, H. Orrego, V. Saldivia, and F. J. Carmichael, "Haemodynamic and organ blood flow responses to sevoflurane during spontaneous ventilation in the rat: a dose-response study," Canadian Journal of Anaesthesia, vol. 39, no. 3, pp. 270-276, 1992.

[29] S. Kocabas, F. Z. Askar, T. Yagdi, C. Engin, and M. Ozbaran, "Anesthesia for ventricular assist device placement in pediatric patients: experience from a single center," Transplantation Proceedings, vol. 45, no. 3, pp. 1009-1012, 2013.

[30] M. S. Slaughter, M. A. Sobieski, C. Gallagher, M. Dia, and M. A. Silver, "Low incidence of neurologic events during long-term support with the HeartMate XVE left ventricular assist device," Texas Heart Institute Journal, vol. 35, no. 3, pp. 245-249, 2008.

[31] N. Kokita and A. Hara, "Propofol attenuates hydrogen peroxideinduced mechanical and metabolic derangements in the isolated rat heart," Anesthesiology, vol. 84, no. 1, pp. 117-127, 1996.

[32] N. Kamada, N. Kanaya, N. Hirata, S. Kimura, and A. Namiki, "Cardioprotective effects of propofol in isolated ischemiareperfused guinea pig hearts: role of KATP channels and GSK$3 \beta$," Canadian Journal of Anesthesia, vol. 55, no. 9, pp. 595-605, 2008 . 
[33] S.-H. Ko, C.-W. Yu, S.-K. Lee et al., "Propofol attenuates ischemia-reperfusion injury in the isolated rat heart," Anesthesia and Analgesia, vol. 85, no. 4, pp. 719-724, 1997.

[34] H.-Y. Sun, F.-S. Xue, Y.-C. Xu et al., "Propofol improves cardiac functional recovery after ischemia-reperfusion by upregulating nitric oxide synthase activity in the isolated rat hearts," Chinese Medical Journal, vol. 122, no. 24, pp. 3048-3054, 2009.

[35] K. H. H. Lim, A. P. Halestrap, G. D. Angelini, and M.-S. Suleiman, "Propofol is cardioprotective in a clinically relevant model of normothermic blood cardioplegic arrest and cardiopulmonary bypass," Experimental Biology and Medicine, vol. 230, no. 6, pp. 413-420, 2005.

[36] N. Hirata, N. Kanaya, N. Kamada, S. Kimura, and A. Namiki, "Differential effects of propofol and sevoflurane on ischemiainduced ventricular arrhythmias and phosphorylated connexin 43 protein in rats," Anesthesiology, vol. 110, no. 1, pp. 50-57, 2009.

[37] R. A. G. Barbosa, S. R. C. J. Santos, P. F. White et al., "Effects of cardiopulmonary bypass on propofol pharmacokinetics and bispectral index during coronary surgery," Clinics, vol. 64, no. 3, pp. 215-221, 2009.

[38] J. Zhao, F. Wang, Y. Zhang et al., "Sevoflurane preconditioning attenuates myocardial ischemia/reperfusion injury via caveolin-3-dependent cyclooxygenase-2 inhibition," Circulation, vol. 128, supplement 1, no. 11, pp. S121-S129, 2013.

[39] M. Shiomi, M. Miyamae, G. Takemura et al., "Induction of autophagy restores the loss of sevoflurane cardiac preconditioning seen with prolonged ischemic insult," European Journal of Pharmacology, vol. 724, pp. 58-66, 2014.

[40] C. Zhou, H. Li, Y. Yao, and L. Li, "Delayed remote ischemic preconditioning produces an additive cardioprotection to sevoflurane postconditioning through an enhanced heme oxygenase 1 level partly via nuclear factor erythroid 2-related factor 2 nuclear translocation," Journal of Cardiovascular Pharmacology and Therapeutics, vol. 19, no. 6, pp. 558-566, 2014.

[41] M. Zaugg, E. Lucchinetti, S. Behmanesh, and A. S. Clanachan, "Anesthetic cardioprotection in clinical practice from proofof-concept to clinical applications," Current Pharmaceutical Design, vol. 20, no. 36, pp. 5706-5726, 2014.

[42] J. L. G. Orriach, M. G. Ortega, M. R. Aliaga, P. Iglesias, M. R. Navarro, and J. C. Mañas, "Prolonged sevoflurane administration in the off-pump coronary artery bypass graft surgery: beneficial effects," Journal of Critical Care, vol. 28, no. 5, pp. 879.e13-879.e18, 2013.

[43] M. Zaugg and E. Lucchinetti, "Sevoflurane-compared with propofol-based anesthesia reduces the need for inotropic support in patients undergoing abdominal aortic aneurysm repair: evidence of cardioprotection by volatile anesthetics in noncardiac surgery," Anesthesiology, vol. 120, no. 5, pp. 1289-1290, 2014.

[44] I. Malagon, K. Hogenbirk, J. van Pelt, M. G. Hazekamp, and J. G. Bovill, "Effect of three different anaesthetic agents on the postoperative production of cardiac troponin $\mathrm{T}$ in paediatric cardiac surgery," British Journal of Anaesthesia, vol. 94, no. 6, pp. 805-809, 2005.

[45] H. Bundgaard, G. von Oettingen, K. M. Larsen et al., "Effects of sevoflurane on intracranial pressure, cerebral blood flow and cerebral metabolism: a dose-response study in patients subjected to craniotomy for cerebral tumours," Acta Anaesthesiologica Scandinavica, vol. 42, no. 6, pp. 621-627, 1998.

[46] G. L. Ludbrook, E. Visco, and A. M. Lam, "Propofol: relation between brain concentrations, electroencephalogram, middle cerebral artery blood flow velocity, and cerebral oxygen extraction during induction of anesthesia," Anesthesiology, vol. 97, no. 6, pp. 1363-1370, 2002.

[47] T. Masai, Y. Sawa, S. Ohtake et al., "Hepatic dysfunction after left ventricular mechanical assist in patients with endstage heart failure: role of inflammatory response and hepatic microcirculation," The Annals of Thoracic Surgery, vol. 73, no. 2, pp. 549-555, 2002.

[48] T. Yamaguchi, Y. Sawa, T. Masai et al., "Hepatic sinusoid endothelial dysfunction plays a role in hyperbilirubinemia in patients following implantation of an LVAD," ASAIO Journal, vol. 43, no. 5, pp. M449-M452, 1997.

[49] L. W. Miller and K. Lietz, "Candidate selection for long-term left ventricular assist device therapy for refractory heart failure," The Journal of Heart and Lung Transplantation, vol. 25, no. 7, pp. 756-764, 2006.

[50] J.-M. Bernard, M.-F. Doursout, P. Wouters, C. J. Hartley, R. G. Merin, and J. E. Chelly, "Effects of sevoflurane and isoflurane on hepatic circulation in the chronically instrumented dog," Anesthesiology, vol. 77, no. 3, pp. 541-545, 1992.

[51] S. De Hert, D. Vlasselaers, R. Barbé et al., "A comparison of volatile and non volatile agents for cardioprotection during onpump coronary surgery," Anaesthesia, vol. 64, no. 9, pp. 953960, 2009.

[52] M. J. S. Heath and M. L. Dickstein, "Perioperative management of the left ventricular assist device recipient," Progress in Cardiovascular Diseases, vol. 43, no. 1, pp. 47-54, 2000.

[53] E. Tuzun, C. Narin, I. D. Gregoric, W. E. Cohn, and O. H. Frazier, "Ventricular assist device outflow-graft site: effect on myocardial blood flow," Journal of Surgical Research, vol. 171, no. 1, pp. 71-75, 2011.

[54] T. Yamagishi, K. Oshima, Y. Hasegawa et al., "Cytokine induction by LVAD in the canine kidney," The Journal of Cardiovascular Surgery, vol. 42, no. 6, pp. 759-768, 2001.

[55] I. Nasu, N. Yokoo, S. Takaoka et al., "The dose-dependent effects of isoflurane on outcome from severe forebrain ischemia in the rat," Anesthesia and Analgesia, vol. 103, no. 2, pp. 413-418, 2006.

[56] S. Mathur, P. Farhangkhgoee, and M. Karmazyn, "Cardioprotective effects of propofol and sevoflurane in ischemic and reperfused rat hearts: role of K(ATP) channels and interaction with the sodium-hydrogen exchange inhibitor HOE 642 (cariporide)," Anesthesiology, vol. 91, no. 5, pp. 1349-1360, 1999.

[57] Y. Zhang, M. G. Irwin, and T. M. Wong, "Remifentanil preconditioning protects against ischemic injury in the intact rat heart," Anesthesiology, vol. 101, no. 4, pp. 918-923, 2004.

[58] T. Annecke, J. C. Kubitz, S. Kahr et al., "Effects of sevoflurane and propofol on ischaemia-reperfusion injury after thoracicaortic occlusion in pigs," British Journal of Anaesthesia, vol. 98, no. 5, pp. 581-590, 2007. 


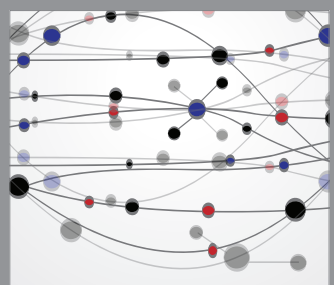

The Scientific World Journal
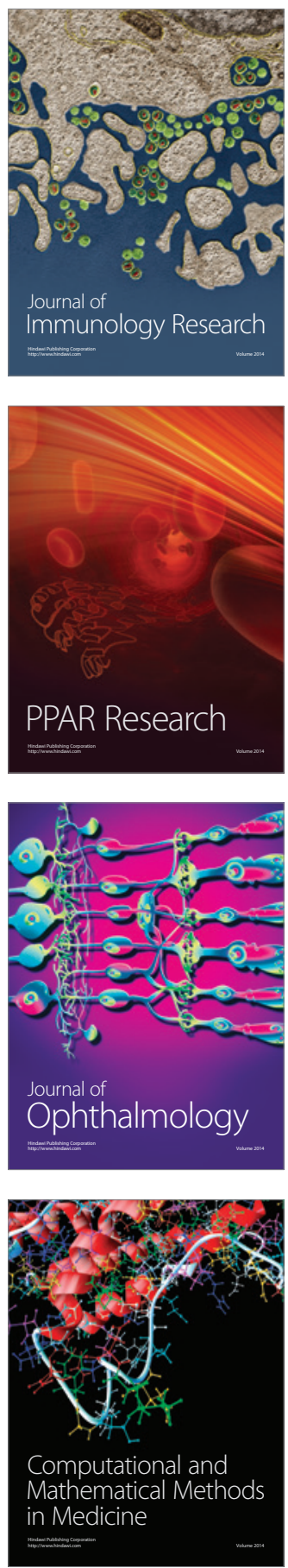

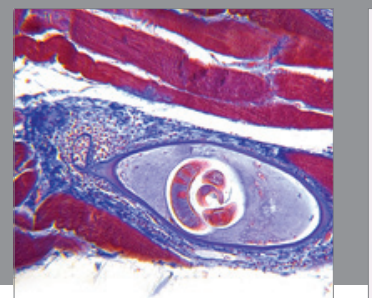

Gastroenterology

Research and Practice
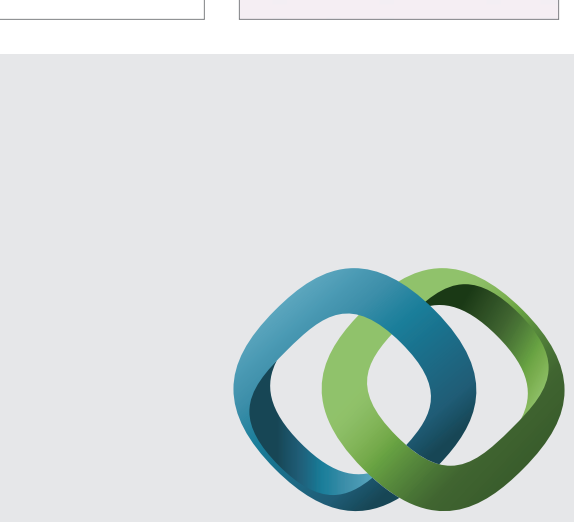

\section{Hindawi}

Submit your manuscripts at

http://www.hindawi.com
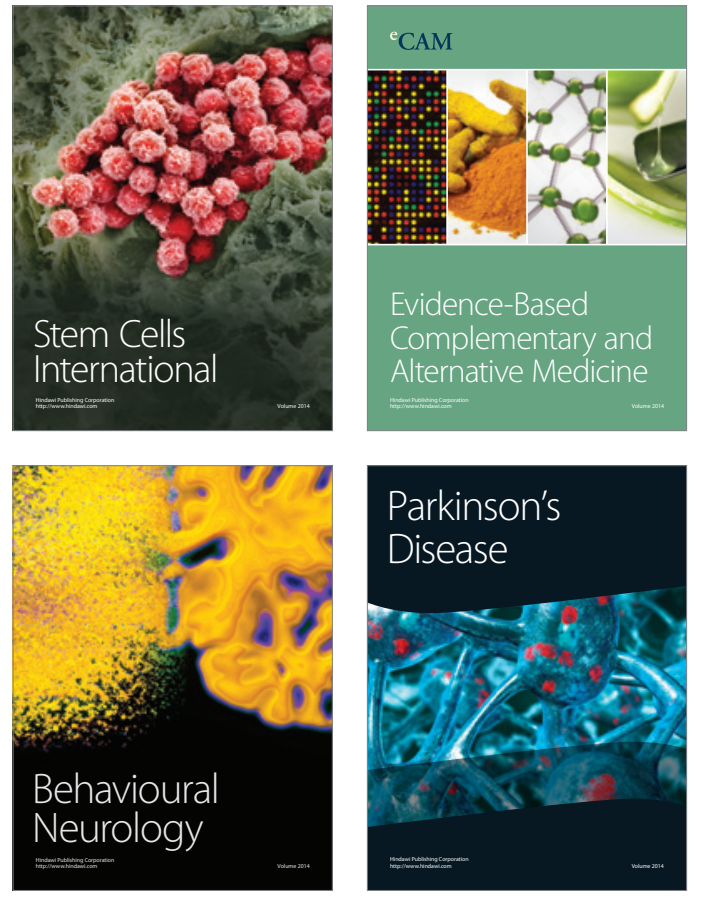
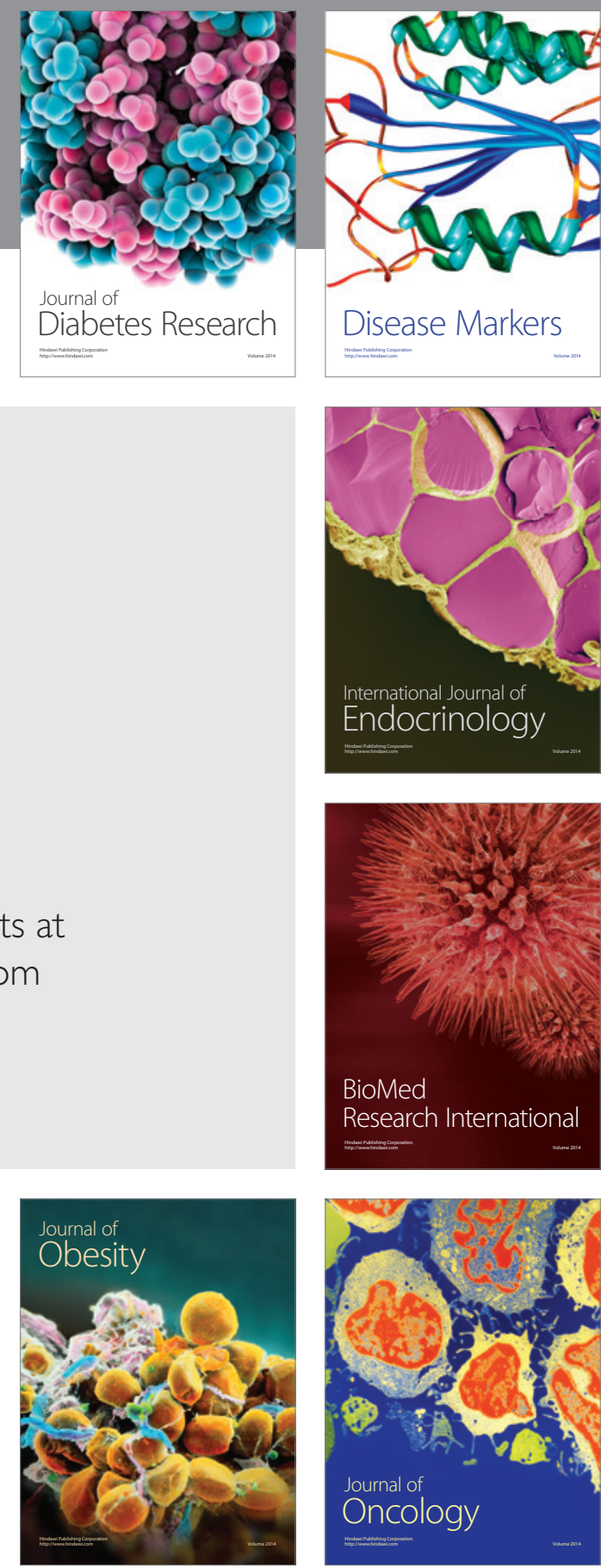

Disease Markers
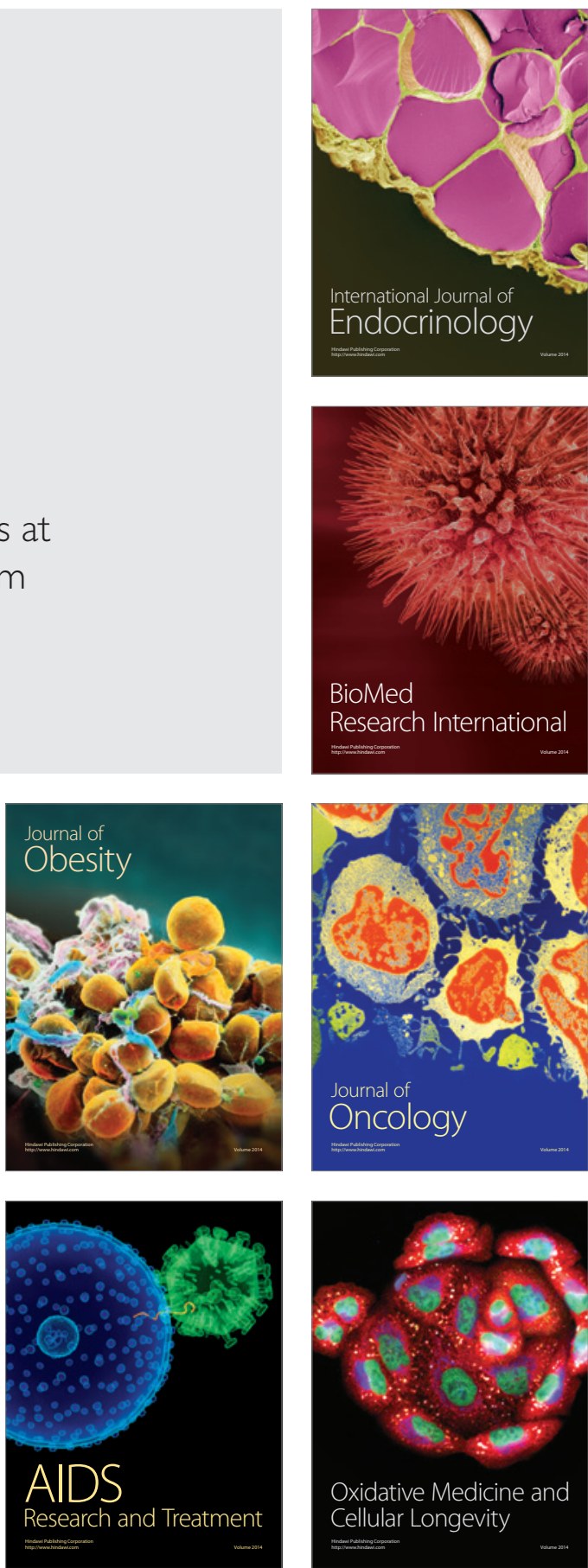